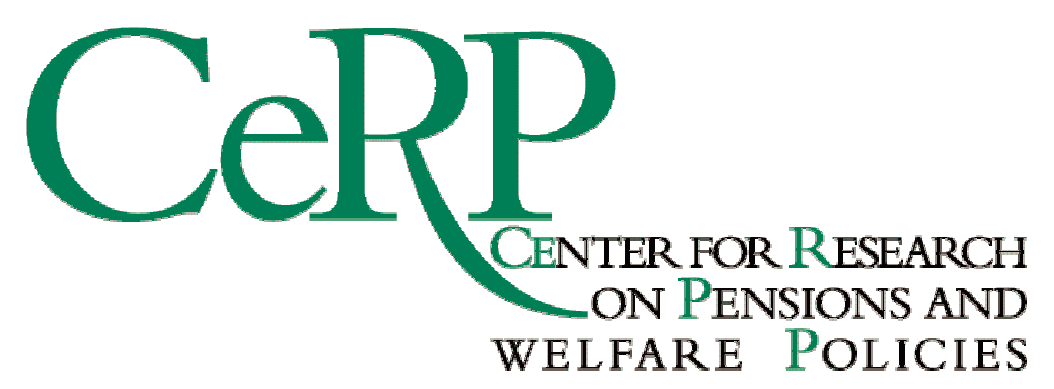

Working Paper 8/01

\title{
SOCIAL SECURITY SYSTEMS AND THE DISTRIBUTION OF INCOME: AN APPLICATION TO THE ITALIAN CASE
}

\author{
Margherita Borella
}

\footnotetext{
* CeRP and University College London Via Real Collegio, 30 10024 Moncalieri (Turin)

Tel.: $\quad+39.011 .6476525$

Fax: $\quad+39.011 .6403680$

E.mail: borella@cerp.unito.it
} 


\begin{abstract}
This paper analyses the distribution of pensioners' income under different Social Security systems. The work focuses in particular on the recent reforms undertaken in the Italian Social Security system.

Simulations, calibrated on Italian male dependent workers earnings histories, show that the new contribution-based scheme (after the reform in 1995) reduces inequality among all groups considered, i.e. private or public dependent workers of different education groups. The generalised Lorenz curve shows that for the overall population considered (one generation of retiring dependent workers) the (small) reduction in average benefit is compensated by the reduction in inequality, with the exception of the highest percentiles. However, within groups with a steeper age-earnings profile (high school and college graduates employed in the private sector) the generalised Lorenz curve associated with the contribution-based scheme is dominated by the distribution associated with the previous earnings-related scheme.
\end{abstract}

I am very grateful to Orazio Attanasio and Elsa Fornero for their help and comments, and to Federico Revelli and participants to CeRP seminars for useful comments. I am indebted to Agar Brugiavini who kindly provided me with the algorithm used to build gross earnings. 


\section{Introduction}

In principle, Social Security systems also aim at redistributing resources towards low-income groups. Earnings based (EB) schemes traditionally include mechanisms in order to actively redistribute income within the insured workers. Floors, ceilings, and survivor benefits are among the tools through which redistribution occurs.

In practice, EB systems may operate redistribution in the opposite direction, i.e. from poor to rich ${ }^{4}$. This kind of redistribution arises from various features of the EB systems, notably from the benefit computation formula, which takes into account only the last (or the last few) wage, and therefore guarantees an overgenerous pension to individuals with steeper earnings profiles, typically high earners.

In this framework, it has been argued (James, 1997) that contribution based (CB) formulae could enhance equity by removing the inequities implicit in the earnings related systems. In particular, the contribution-based scheme removes unequal treatments like early retirement benefits and advantages to workers with steep earnings profiles. However, other inequities may be introduced by the new system: the treatment of low income groups, and especially the treatment of workers who have non-continuous working careers, play a major role in assessing how much a Social Security system is able to redistribute income to low income groups.

This work focuses in particular on the recent reforms undertaken in the Italian Social Security system: between 1992 and 1995 the Italian system was deeply reformed and is now moving from an earnings-related to a

\footnotetext{
${ }_{1}^{1}$ Among others, the point has been raised by Castellino (1995) and James (1997).
} 
contribution-based scheme ${ }^{6}$. The pre-1992 system was highly generous and redistributive, characterised by high replacement rates and various forms of redistribution of income from rich to poor. However, often redistribution operated in a perverse way, as highlighted in Castellino (1995).

From a redistributive earnings-related pension formula, the system is gradually moving to a contribution-based one with no direct redistributive aim ${ }^{1}$. According to the 1995 reform, after the (long) transition towards the new regime, the benefit will be based on the payroll taxes paid during the entire working period, (virtually) capitalised at the GDP nominal growth rate and converted into an annuity according to actuarial fairness.

The objective of this paper is to study a particular aspect of the problem: the distributional implications deriving by the determination of the benefit on the basis of the entire working history of the individuals as opposed to the earnings-related scheme in which the benefit is computed on the basis of the last few years' wages.

The study is conducted through a simulation procedure which allows to construct an earnings profile for each individual. In order to make the comparison among the two benefit formulae, individuals are assumed to have continuous and long careers. In the Italian earnings-related system, however, it was possible to receive a "seniority" pension after 35 years of contributions (reduced to 20 years for public sector dependent workers) without any actuarial correction. This feature was clearly an additional benefit offered to workers with continuous careers who could retire at a relatively young age.

\footnotetext{
2 The transition period, however, will be very long, as only workers who entered the labour market in or after 1996 will receive a pension completely computed according to the contribution-based scheme.

${ }^{3}$ However, there will still be redistribution between married and unmarried males and between men and women.
} 
After the 1995 reform will be fully phased in, however, seniority pensions will disappear and uniform rules will apply to all workers.

It should also be noted that the effect of the reforms for individuals with discontinuous careers, who are likely to experience low lifetime earnings, are not analysed in this framework. The distributional impact of the reform on the lowest percentiles of the population requires a different kind of analysis and is left for future research.

The parameters needed are obtained from an estimation of the income process based on Italian panel data, drawn from the Bank of Italy Survey on Households' Income and Wealth. Having simulated the earnings history for individuals of a particular cohort, the pre-1992 and the post-1955 pensions are computed for each individual and the resulting distribution is analysed.

Results show that the new contribution-based scheme (after the reform in 1995) reduces inequality among all groups considered, i.e. private or public dependent workers of different education groups.

In section 2 an overview of the Italian Social Security system and of its recent reforms are reported, while in section 3 the formulae used to compute the benefits arising from different social security formulae are described. Section 4 reviews the data used and the methodology used for simulating the earnings profiles; and section 5 describes the results. Section 6 concludes.

\section{The Social Security System in Italy}

The reforms that took place in Italy in 1992 and in 1995 have deeply changed the pension system. The main features of the traditional pre-1992 system and of the new system resulting after the last reform in 1995 (promulgated during the Dini government) can be summarised as follows. 
The traditional system was characterised by an earnings-related pension formula; it was highly generous and redistributive, characterised by high replacement rates and various forms of redistribution of income from rich to poor. However, different schemes were (and still are) in place with different rules. In the main scheme, the Pension Fund for Private Employees (FPLD), the pension was based on the $2 \%$ of the average of the last five years multiplied by the number of working years. In the State scheme, for public employees, the pension was computed with the same mechanism but on the final wage. The system aimed to be redistributive: floors and ceilings were in place in order to enhance equity, as well as generous survivors benefits, the computation of virtual contributions for workers temporarily out of the labour force and so on.

However, as highlighted in Castellino (1995), the old system was often redistributive in a perverse way. In particular, if floors and ceilings were operating in the sense of redistributing from rich to poor, other features of the old pension system were operating in the opposite direction. Specifically, as the earning based benefits were computed on the basis of the last 5 years wages (or even the last wage for public-sector workers) employees with increasing wage profiles (typically high earners) ended up with overgenerous pensions.

In addition, "seniority" pensions were in place with different rules for different categories of workers: for private sector employees it was possible to claim a seniority pension after 35 years of work, while public sector employees could retire after 20 years of work (15 years for married women). In both cases, seniority pensions were computed with the same mechanism as the old-age pensions, without any actuarial correction for age difference at retirement. 
The effect of within-cohort redistribution in the old system is the result of all those features, and it is not clear a priori in which direction it works.

From a redistributive earnings-related pension formula the system is gradually moving to a contribution-based one with no direct redistributive feature. After the 1995 reform the pension is based on the payroll taxes paid during the entire working period (virtually) capitalised at the GDP nominal growth rate and converted in annuity according to actuarial fairness. Ceilings still apply in the sense that contributions are not paid on the fraction of earnings above a certain threshold. As the benefit is computed on the basis of the contributions paid, however, ceilings do not have any redistributive features Different schemes and seniority pensions will gradually disappear, and flexibility of retirement age is introduced. In particular, workers can retire before reaching age 65 , either if they paid contributions for not less than 40 years, or if they are aged 57 or more and the benefit they are entitled to is greater than 1.2 times the yearly income support provided to the elderly in needs ${ }^{1}$. That limit does not apply when workers reach age 65: at that age any worker can claim his pension and, if eligible, means-tested old-age income support.

\footnotetext{
${ }^{4}$ That is, after the 1995 reform will be fully in place. As previously described, individuals who started working in or after 1996 will receive a benefit computed according to the 1995 reform. Individuals who were already active in the labour force in 1995 will receive a pension computed with the pro-rata mechanism. For a detailed exposition of the Italian Social Security system and its recent reforms, see for example Brugiavini and Fornero (2001) and Brugiavini (1999).

${ }^{5}$ In fact, this is an advantage offered to high-income earners if the composition of the pension portfolio is inefficiently unbalanced in favour of the pay-as-you-go component. ${ }^{6}$ Means-tested income support is provided in Italy to every person aged 65 or more.
} 


\section{The earnings- and contribution-based formulae in Italy}

In order to study the distributional impact of earnings- and contributionbased formulae, two scenarios have been built: the earnings based (EB) and the contribution based (CB) scheme. As previously described, the EB scheme, i.e. the method that was in place in Italy before the 1992 reform, is an earnings related pension formula: the amount of the benefit is computed on the basis of the last 5 years average earnings, multiplied by a coefficient equal to 0.02 and by the number of years during which the worker has paid the contribution to the Social Security system:

$$
P_{E B}=a * 0.02 * \sum_{i=1}^{5} w_{\text {age }-i+1} / 5
$$

where age is the individual's age in his final working year, $w$ is his gross yearly earnings indexed for inflation, and $a$ is the number of years the individual has been active in the labour market. This formula is modified for public sector dependent workers so that the average of the last five wages is replaced by the last wage $\left(w_{\text {age }}\right)$.

The $\mathrm{CB}$ scheme is a contribution-based formula according to which the contributions paid by the worker throughout his life are virtually capitalised at a rate that reflects GNP growth. Actuarial fairness is achieved by multiplying the present value of the contributions by a coefficient that reflects the age of the person retiring from the job market, as well as demographic and GNP growth. The $\mathrm{CB}$ pension, for all categories of workers, is then computed as:

$$
P_{C B}=\left(\sum_{i=\underline{a}}^{a g e} c_{i} *(1+g)^{a g e-i}\right) \cdot \delta_{\text {age }}
$$

where $c_{i}$ is the contribution paid by the worker at age $i, g$ is GNP growth (assumed to be constant and equal to $1.5 \%$ in the simulations), $\delta$ is a 
coefficient of actuarial fairness and $\underline{a}$ is the age at which the worker entered the labour market.

It is clear that in order to compute the benefit deriving from scheme EB and scheme $\mathrm{CB}$ it is necessary to know the entire earnings history of each individual. The simulation technique used to build such a population is described in the next section.

Floors and ceilings are in place in the earning based system, and lower and upper limits on pensionable earnings have been also introduced in the new contribution based system. Computation of the benefits for individuals in the simulated population should take into account this feature. However, in what follows the simulated population will include only dependent workers with continuous careers, and in this setting floors and ceilings never become binding.

Using the simulated earnings histories it is therefore possible to compute the benefits for each individual according to the two different schemes, and to study the distributional implications of the pension formulae considered. Simulated earnings profiles represent gross earnings net of Social Security contributions. In order to simplify the comparison between the two regimes, a constant payroll tax rate equal to $32.7 \%$ has been applied, as this was the payroll tax rate effective in 1998. Of the Social Security contributions, 8.89\% is paid by the worker, while the remaining $23.81 \%$ is paid by the employer.

\section{Earnings Simulation}

In order to build the age-earnings profiles needed to implement the simulations, the panel data set in the Bank of Italy Survey of Households' Income and Wealth (SHIW) has been used. The panel data are available for the years 1989, 1991, 1993, 1995, and 1998. The earnings process for each 
individual is assumed to be the sum of a deterministic observable component and a stochastic unobservable component:

$$
y_{i t}^{j}=X_{i t}^{j \prime} \beta+u_{i t}^{j}
$$

where $y_{i t}^{j}$ is the natural logarithm of real gross earnings of the $i$-th individual aged $j$ at time t. $X_{i t}^{a}$ is a $(k \times 1)$ vector of observable variables, $\beta$ is a $(k \times 1)$ vector of unknown parameters, and $u_{i t}^{a}$ is an error term which represents unobserved characteristics determining earnings. The dependent variable is gross earnings (net of Social Security contributions) of male dependent workers working full time and observed at least for two consecutive waves. Annual gross earnings have been deflated using the ISTAT consumer price index, and they are expressed in 1998 prices.

The sample obtained has been divided into groups according to the sector of activity (private/public) and to the education level (high school dropout, high school graduate, college graduate). In addition, in order to take into account cohort effects, six year-of-birth groups have been created. The youngest cohort is formed by individuals born between 1963 and 1967 included, and the eldest by individuals born between 1938 and 1942 included. In the analysis, individuals in the youngest cohort are considered as aged 24 in 1989, 26 in 1991 and so on. The other cohorts are treated similarly. Regressions are then performed by education group using as regressors a polynomial in age and cohort dummies, both for private and for public employees? Estimated coefficients for the age polynomial for each education/sector group are then used to build earnings profiles.

Gross earnings-age profiles for the different groups of interest are shown in Figures 1 and 2. The profiles shown are in levels, in 1998 prices, and are the 
ones relative to the youngest cohort. Public sector workers display, on average, flatter earnings profiles. In particular, for college and high school graduate workers the first wage is quite close in the two sectors considered; however, the average yearly wage rate of growth in the private sector is $2 \%$ per year for college graduates and $1.5 \%$ for high school graduates, while in the public sector the average rates of growth are $0.9 \%$ and $0.5 \%$ respectively. High school dropout workers exhibit a similar profile in both sectors, with an average yearly wage rate of growth of about $0.5 \%$.

In order to simulate a different age-earnings pattern for each individual, an estimate of the parameters underlying the structure of the unobservable component of earnings is needed. Using the results in Borella (2001), the unobserved component of earnings for individual $i$ of age $j$ is decomposed into a permanent component which is time invariant $\left(\mu_{i}\right)$ and an $\operatorname{AR}(1)$ component $\left(z_{i t}^{j}\right)^{\text {. }}$.

$$
\begin{aligned}
& u_{i t}^{j}=\mu_{i}+z_{i t}^{j} \\
& z_{i t}^{j}=\alpha z_{i, t-1}^{j-1}+\omega_{i t}^{j}
\end{aligned}
$$

where $\omega_{i t}^{j}$ is an i.i.d. stochastic process with zero mean and variance $\sigma_{\omega}^{2}$, and $\mu_{i}$ is i.i.d. with zero mean and variance equal to $\sigma_{\mu}^{2}$. The $\operatorname{AR}(1)$ component arises from a finite process starting at age $\underline{a}$, the age at which individuals enter the labour market.

The variances of this process can be summarised by the following recursions:

$$
\operatorname{Var}\left(u_{i t}^{j}\right)=\sigma_{\mu}^{2}+\operatorname{Var}\left(z_{i t}^{j}\right)
$$

\footnotetext{
${ }^{7}$ It is not possible to separately identify age, cohort and time effects as they are linear combinations of one another. In the analysis it is therefore assumed that the time effects are orthogonal to a time trend.

8 The average rate of growth of real GNP between 1989 and 1998 has been in Italy equal to $1.5 \%$.

9 The analysis in Borella (2001) shows that this is the best characterization of the earning process that can be obtained with the Italian data (SHIW).
} 
where:

$$
\operatorname{Var}\left(z_{i t}^{\underline{a}}\right)=\sigma_{\underline{a}}^{2}
$$

and:

$$
\operatorname{Var}\left(z_{i t}^{j}\right)=\alpha^{2} \operatorname{Var}\left(z_{i t-1}^{j-1}\right)+\sigma_{\omega}^{2} \quad \text { with } j>\underline{a}
$$

The parameters used to calibrate the simulation are based on the estimates in Borella (2001). Parameter estimates are shown in tables 1 and 2. In the simulation, all the unobservable components are assumed to be drawn from normal distributions, with zero mean and variance given by the variance estimates.

The simulated population has been built according to the structure of the 1998 sample of male dependent workers, employed both in the private and in the public sector. Of 15,000 observations, 30\% are public sector and $70 \%$ are private sector employees. In the public sector, $18 \%$ of workers have a college degree, $42 \%$ are high school graduates and the rest has with a primary school degree. In the private sector, 63\% of workers have only a primary school degree, $32 \%$ are high school graduates and only 5\% are college graduates.

In the artificial population, individuals are assumed to start working at age 22 (college graduates at 25) and to retire at age 60.

\section{Results}

Having simulated the earnings profiles for a number of individuals as described in the preceding section, it is possible to compute the benefits resulting from the two scenarios considered: the earnings-related and the contribution based formulae.

Table 3 reports the mean of the final wage, and of the pension computed both with the earning based and with the contribution based formula. Gross 
yearly earnings (gross of Social Security contributions and of the income tax) are reported, as well as gross yearly pensions. For the whole sample $(15,000$ observations) the final year gross wage is roughly 41.5 million lira; the yearly gross pension computed with the earnings-related formula is 32.7 million lira while the benefit computed with the contribution based formula is 32 million lira.

Those results also depend on the assumption of a capitalisation of contributions at a rate equal to $1.5 \%$. With the economy growing at a faster rate, the contributions paid by each worker would be virtually capitalised at a higher rate and the resulting CB benefit would be more generous. However, as the distribution of the benefits is the same for different assumptions on GNP growth, results are shown only for this base case.

Figures in table 3 imply an average gross replacement ratio of $78 \%$ for the EB pension, and of $77 \%$ for the $\mathrm{CB}$ benefit, where the figures are obtained dividing the average gross pension benefit by the average final year gross wage. This procedure amounts to compute the weighted average of the individual replacement ratios, weighted by the final wage.

As individual data are available, it is also possible to compute the individual replacement ratio, defined as the ratio of the individual pension benefit to the individual final wage, and to study its distribution. Unweighted averages of individual replacement rates are reported in table 4 . The average of the individual replacement ratio under the EB regime is about $80 \%$, while under the $\mathrm{CB}$ regime this is about $83 \%$. Turning to the sub-groups considered, table 4 shows a tendency of a higher replacement rate when the benefit is computed according to the contribution-based method. The reverse is true for high school and college graduates employed in the private sector. For those two groups the pension computed with the CB formula is lower than the benefit that would have been received under the EB regime; the resulting 
gross replacement ratio falls from $80 \%$ to $72 \%$ for high school graduates and from $77 \%$ to $62 \%$ for college graduates.

In tables 5 and 6 the deciles of the distribution of the gross replacement rates are shown for the different groups considered. For the whole population the median replacement rates in the $\mathrm{EB}$ and the $\mathrm{CB}$ schemes are quite close. In both regimes, however, the replacement rates vary quite considerably: under the EB scheme, for example, the value of the replacement rate at the last decile is equal to $98 \%$, while at the first decile it falls to $67 \%$. The deciles under the $\mathrm{CB}$ regime range from $58 \%$ to $112 \%$.

The distribution of the EB benefit for the public sector follows from the fact the only the last wage is used to compute the benefit (as opposed to the last five years used in the private sector). This implies a gross replacement rate of $78 \%$ for high school dropouts and high school graduates, and of $72 \%$ for college graduates, who have a shorter working career.

In table 7 the average gross replacement ratios by wage decile are reported: in both schemes, the lower the wage decile, the higher the replacement ratio the system ensures to the individual. Both for the whole population and for the two sectors separately, the $\mathrm{CB}$ compared to the $\mathrm{EB}$ scheme provides higher replacement rates to individuals in the bottom wage deciles, and conversely, the lower replacement rates to individuals who are in the higher wage deciles. Turning to the level of the computed benefits, in table 8 a few measures of inequality are computed for the two pensions and for the different groups considered, in order to summarise the departure of the distribution from equity. The coefficient of variation is the ratio of the standard deviation of the variable of interest to its mean: the higher the coefficient of variation, the higher the inequality. The standard deviation of the variables in logarithm is also shown, and higher values also in this case represent higher inequality. Finally, the Gini coefficient is computed: it is defined as the ratio to the mean 
of half the average over all pairs of the absolute deviations between people. If the distribution of the variable considered is perfectly egalitarian, the Gini coefficient is 0 , while if one individual owns the total amount available, while the others own nothing, the Gini coefficient is equal to 1.

The various indices give the same picture: the pension computed with the CB formula appears to have a more equal distribution then the EB pension.

Turning to the different categories of workers considered, in the private sector the reduction in inequality induced by the $\mathrm{CB}$ pension is lower compared to its effect in the public sector This is because the EB pension in the public sector was computed on the basis of the last wage only, thus reflecting its variability, and not on an average wage.

Graphical analysis based on Lorenz curves is a useful tool in comparing the inequality exhibited by different distributions. As the Lorenz curves for the two distributions are very close to each other, the transformed Lorenz curve has been built for the whole population as well as for the different sectors and education groups considered (Figures 3-6). The $\mathrm{x}$-axis is the cumulative fraction of population - starting from the poorest - as in the standard Lorenz curve, while on the y-axis the difference between the cumulative fraction of the variable of interest and the line of complete equality (the 45 degree line) is plotted. The lower the curve, the less unequal is the distribution of the variable considered. The graphs show that the two curves do not cross each other, so that, in terms of inequality, the distribution of the $\mathrm{CB}$ pension always Lorenz dominates the distribution of the EB pension ${ }^{4}$.

\footnotetext{
10 It should be noticed that the inequality measures considered here do not exhibit the property of decomposition, so that overall inequality cannot be decomposed in an additive way into inequality within and between groups. It is nonetheless possible, however, to assess the effect of the different pension formulae within the groups considered in the analysis.

11 As the curves do not cross each other, the Lorenz curve gives the ordering according to inequality.
} 
It should be noticed that, as no individual in the simulated population is hitting the floor or the ceiling, the two pensions computed in this case contain no direct redistributive feature. The reduction in inequality therefore follows uniquely from the fact that in one case (the EB situation) the pension is computed on the basis of the last five years of earnings, while in the other the benefit is computed using the entire earnings history of the individual.

As the variables of interest differ in their means, the generalised Lorenz curves (Shorrocks, 1983) are also plotted (Figures 7-10). This is a plot of the cumulative fraction of the population against the cumulative fraction of the variable of interest multiplied by its mean. In this setting, the distribution with the higher mean cannot be dominated, as the end point of the curve is the overall mean, but if the distribution with the higher mean is also more unequal than the other, it is possible that the curves cross each other and none of the distributions dominates the other. Generalised Lorenz dominance of one variable to another implies that the social welfare associated with the former is greater than social welfare associated with the latter In this setting the population considered is only a sub-group of the whole population (namely, one generation of retiring dependent workers); this implies that the implications drawn are valid only for the sub-group considered and do not take into account the welfare of the society as a whole. For the whole population considered (Figure 7) the two curves cross each other only in the last part, while for all the other percentiles the pension computed with the $\mathrm{CB}$ formula dominates the pension computed with the EB formula.

The analysis for each of the sub-groups considered (Figures 8-10) reveals that the $\mathrm{EB}$ pension dominates the $\mathrm{CB}$ pension only for the sub-groups of high

12 Where the social welfare function is non-decreasing in each of its arguments and sconcave. For an overview of these concepts, see Atkinson (1983) and Deaton (1997). 
school and college graduates employed in the private sector. For those groups, the reduction in average pension is not compensated by the reduction in inequality. On the contrary, graduates in the public sector suffer a (small) drop in average pension which is compensated by the drop in inequality. For the other groups the $\mathrm{CB}$ pension dominates.

\section{Conclusions}

This study analysed the distribution of pensioners' income under different Social Security systems. In particular, the distributional impact of a pension deriving from an earnings-related formula and a pension deriving from a contribution-based formula has been studied. Simulations have been calibrated on Italian male dependent workers earnings histories and on the Italian Social Security system, pre- and post-reform.

Results show that the new contribution-based scheme (after the reform in 1995) reduces inequality among all groups considered, i.e. private or public dependent workers of different education groups. The generalised Lorenz curve shows that for the overall population considered (one generation of retiring dependent workers) the (small) reduction in average benefit is compensated by the reduction in inequality, with the exception of the highest percentiles. However, within groups with a steeper age-earnings profile (high school and college graduates employed in the private sector) the generalised Lorenz curve associated with the contribution-based scheme is dominated by the distribution associated with the old earnings-related scheme. 


\section{References}

Atkinson, A. B. (1983) "The Economics of Inequality", second edition, Oxford University Press, Oxford.

Borella, M. (2001) "The Error Structure of Earnings: an Analysis on Italian Longitudinal Data", CeRP Working Paper $\mathrm{N}^{\circ}$ 7/01.

Brugiavini, A. (1999) "Social Security and Retirement in Italy", in J. Gruber and D. Wise. eds., Social Security and Retirement around the World, The University of Chicago Press.

Brugiavini, A. and E. Fornero (2001) "Pension Provision in Italy", forthcoming in Richard Disney and Paul Johnson Eds., Pension Systems and Retirement Incomes across OECD Countries, Edward Elgar, London 2001.

Castellino, O. (1995) "Redistribution Between and Within Generations in the Italian Social Security System", Ricerche Economiche, 49, 317-327.

Deaton, A. (1997) "The Analysis of Household Surveys: a Microeconometric Approach to Development Policy", Published for the World Bank, The Johns Hopkins University Press.

James, E. (1997) "Pension Reform: Is There an Efficiency-Equity TradeOff?”, World Bank Working Paper n. 1767.

Shorrocks, A. F. (1983) “Ranking Income Distributions”, Economica, 50, 3-17. 


\section{Figure 1}

Private Sector - Males

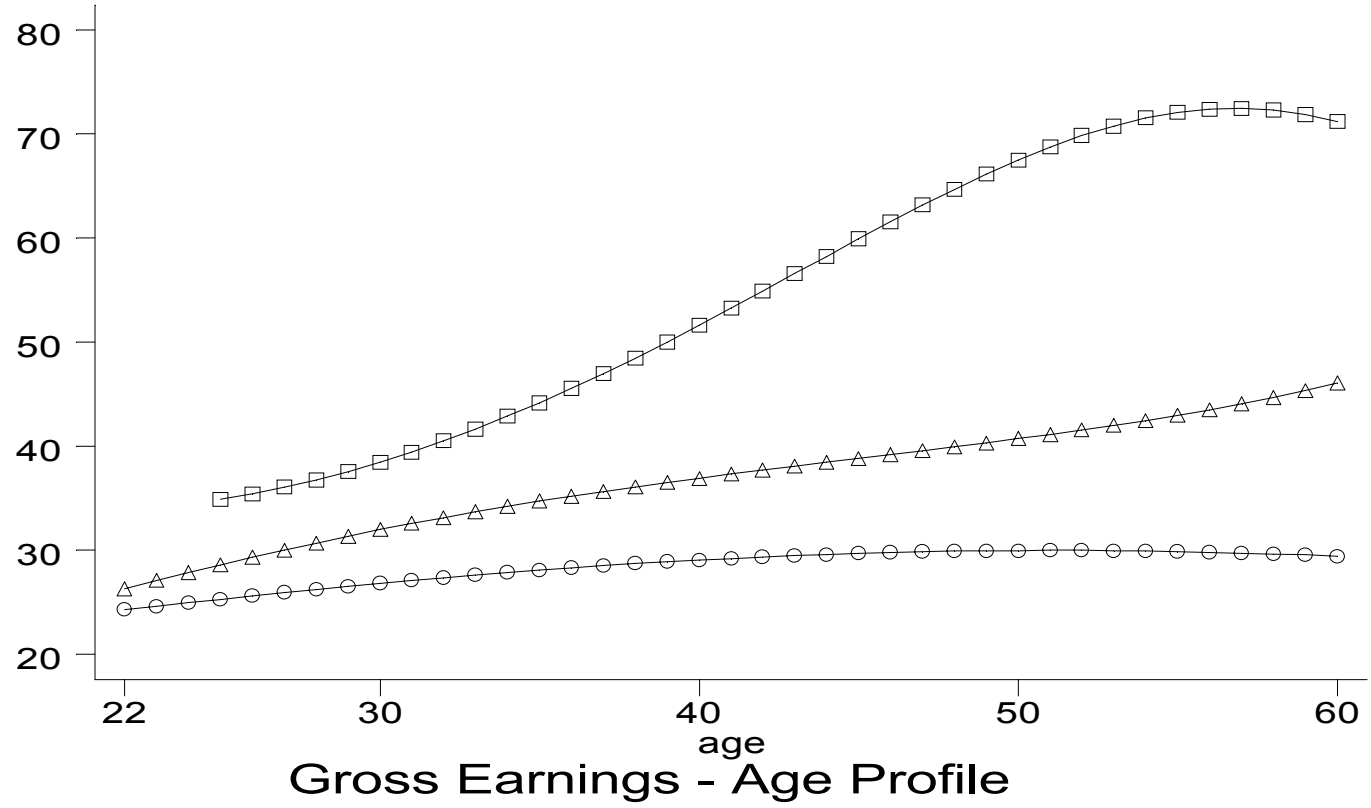

Figure 2

Public Sector - Males

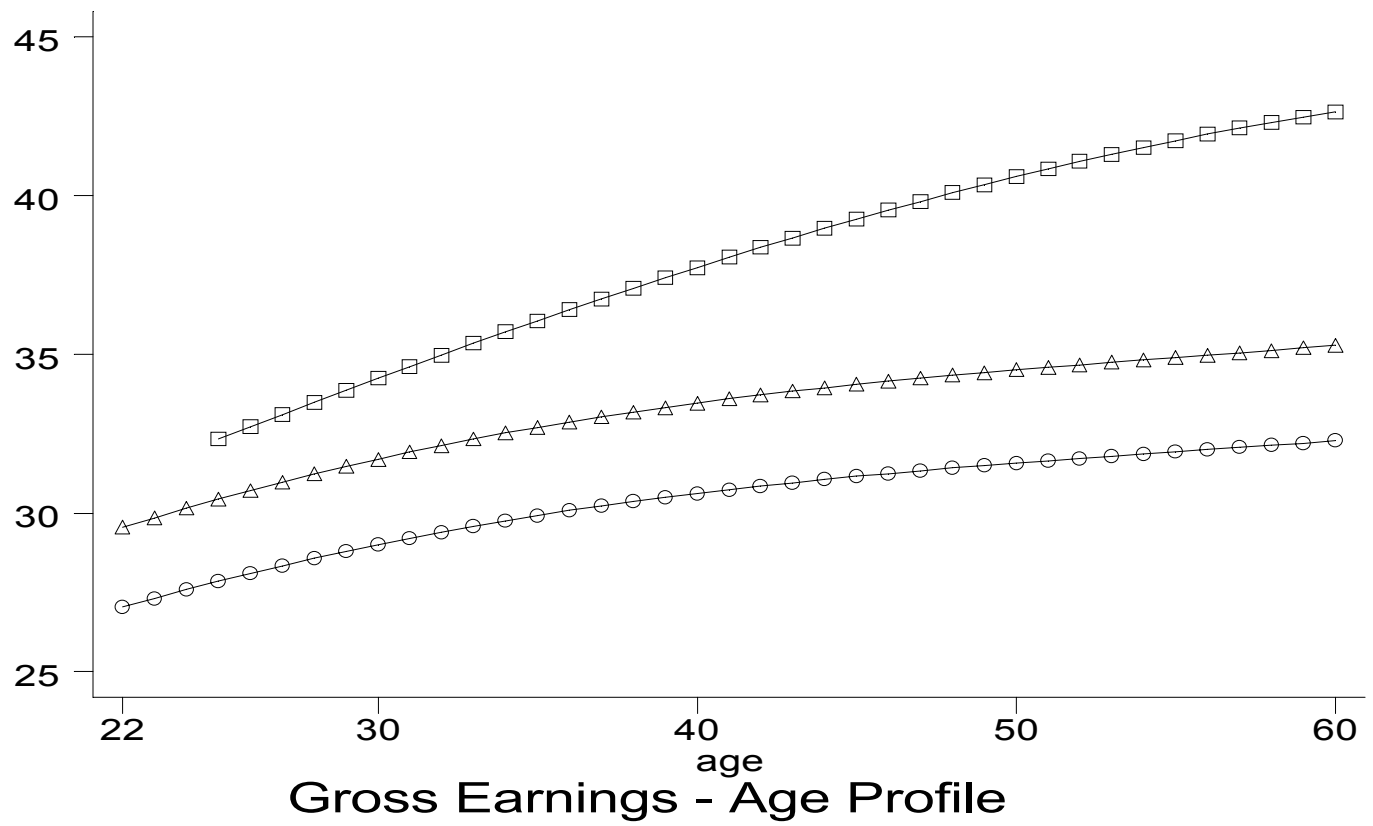

$\square$ : College Graduates

$\triangle$ : High School Graduates

O: High School Dropouts

Gross Earnings are net of Social Security contributions. Y-axis labels are expressed in million liras at 1998 prices, for the cohort born in 1965. 
Parameter estimates for the earnings process

Table 1: Private sector dependent workers

\begin{tabular}{|l|c|c|}
\hline & $\begin{array}{c}\text { Education: } \\
\text { high school } \\
\text { dropout }\end{array}$ & $\begin{array}{c}\text { Education: } \\
\text { high school and } \\
\text { college }\end{array}$ \\
\hline$\sigma_{\eta}^{2}$ & 0.027 & 0.032 \\
$t$-stat & $(5.55)$ & $(3.88)$ \\
$\alpha$ & 0.545 & 0.533 \\
$t$-stat & $(5.41)$ & $(3.23)$ \\
$\sigma_{\omega}^{2}$ & 0.034 & 0.034 \\
$t$-stat & $(8.91)$ & $(6.87)$ \\
$\sigma_{\underline{a}}^{2}$ & 0.032 & 0.045 \\
$t$-stat & $(1.94)$ & $(1.94)$ \\
\hline Sumof Squared & 0.0229 & 0.0558 \\
Residuals & 2106 & 1223 \\
\hline . of Obs. & & \\
\hline
\end{tabular}

Table 2: Public sector dependent workers

\begin{tabular}{|l|c|c|}
\hline & $\begin{array}{c}\text { Education: } \\
\text { high school } \\
\text { dropout }\end{array}$ & $\begin{array}{c}\text { Education: } \\
\text { high school and } \\
\text { college }\end{array}$ \\
\hline$\sigma_{\eta}^{2}$ & 0.004 & -0.060 \\
$t$-stat & $(0.52)$ & $(-1.07)$ \\
$\alpha$ & 0.712 & 0.908 \\
$t$-stat & $(7.70)$ & $(17.40)$ \\
$\sigma_{\omega}^{2}$ & 0.021 & 0.022 \\
$t$-stat & $(6.59)$ & $(7.24)$ \\
$\sigma_{a}^{2}$ & 0.018 & 0.098 \\
$t$-stat & $(1.71)$ & $(1.42)$ \\
\hline $\begin{array}{l}\text { Sum of Squared } \\
\text { Residuals }\end{array}$ & 0.0147 & 0.0259 \\
$N$. of Obs. & 758 & 1144 \\
\hline
\end{tabular}


Table 3: Simulation Results (Means)

\begin{tabular}{|c|c|c|c|c|}
\hline & $\begin{array}{l}\text { Number of } \\
\text { Individuals }\end{array}$ & $\begin{array}{l}\text { Final } \\
\text { Wage }\end{array}$ & $\begin{array}{c}\text { Earnings } \\
\text { Based (EB) } \\
\text { Benefit }\end{array}$ & $\begin{array}{c}\text { Contribution } \\
\text { Based (CB) } \\
\text { Benefit }\end{array}$ \\
\hline Whole sample & 15000 & 41.667 & 32.679 & 32.092 \\
\hline Private & 10600 & 42.101 & 33.313 & 31.933 \\
\hline High School Dropouts & 6678 & 33.611 & 27.176 & 28.371 \\
\hline High School Graduates & 3392 & 52.694 & 41.091 & 36.382 \\
\hline College Graduates & 530 & 81.289 & 60.857 & 48.328 \\
\hline Public & 4400 & 40.619 & 31.153 & 32.475 \\
\hline High School Dropouts & 1760 & 36.293 & 28.309 & 30.367 \\
\hline High School Graduates & 1848 & 41.107 & 32.064 & 33.656 \\
\hline College Graduates & 792 & 49.091 & 35.346 & 34.406 \\
\hline
\end{tabular}

Notes: - Values are expressed in million liras;

- Final wage is gross of income tax and of Social Security contributions;

- EB and CB benefits are gross of income tax. 
Table 4: Individual Gross Replacement Ratio

\begin{tabular}{|l|c|c|}
\hline \multicolumn{1}{|l|}{ Whole sample } & EB & CB \\
\hline Private & 0.805 & 0.833 \\
High School Dropouts & 0.819 & 0.820 \\
High School Graduates & 0.801 & 0.885 \\
College Graduates & 0.771 & 0.722 \\
Public & 0.769 & 0.618 \\
\hline High School Dropouts & 0.780 & 0.866 \\
High School Graduates & 0.780 & 0.871 \\
College Graduates & 0.720 & 0.901 \\
\hline
\end{tabular}

Note: The replacement ratio is computed as the average of the ratio of the individual's yearly gross pension to the yearly gross earnings (gross of income tax and of social security contributions paid by the worker). 
Table 5: Individual Gross Replacement Ratio: deciles

\begin{tabular}{|c|l|l|l|l|l|l|}
\hline \multicolumn{4}{|c}{ Whole Population } & \multicolumn{2}{c|}{ Private Sector } & \multicolumn{2}{c|}{ Public Sector } \\
\hline Percentage & EB & CB & EB & CB & EB & CB \\
\hline 10 & 0.67 & 0.58 & 0.65 & 0.58 & 0.72 & 0.57 \\
20 & 0.72 & 0.65 & 0.69 & 0.65 & 0.78 & 0.65 \\
30 & 0.75 & 0.71 & 0.73 & 0.70 & 0.78 & 0.72 \\
40 & 0.78 & 0.76 & 0.77 & 0.75 & 0.78 & 0.77 \\
50 & 0.78 & 0.81 & 0.80 & 0.80 & 0.78 & 0.83 \\
60 & 0.78 & 0.86 & 0.84 & 0.85 & 0.78 & 0.89 \\
70 & 0.83 & 0.92 & 0.88 & 0.91 & 0.78 & 0.96 \\
80 & 0.89 & 1.00 & 0.93 & 0.98 & 0.78 & 1.05 \\
90 & 0.98 & 1.12 & 1.01 & 1.08 & 0.78 & 1.19 \\
\hline
\end{tabular}


Table 6: Individual Gross Replacement Ratio: deciles by education group

\begin{tabular}{|c|c|c|c|c|c|c|}
\hline & \multicolumn{6}{|c|}{ Earnings Based } \\
\hline & \multicolumn{3}{|c|}{ Private Sector } & \multicolumn{3}{|c|}{ Public Sector } \\
\hline Percentage & HS dropouts & H.S. & College & H.S. dropouts & H.S. & College \\
\hline 10 & 0.66 & 0.64 & 0.60 & 0.78 & 0.78 & 0.72 \\
\hline 20 & 0.71 & 0.68 & 0.65 & 0.78 & 0.78 & 0.72 \\
\hline 30 & 0.75 & 0.72 & 0.69 & 0.78 & 0.78 & 0.72 \\
\hline 40 & 0.78 & 0.75 & 0.72 & 0.78 & 0.78 & 0.72 \\
\hline 50 & 0.82 & 0.79 & 0.76 & 0.78 & 0.78 & 0.72 \\
\hline 60 & 0.85 & 0.82 & 0.80 & 0.78 & 0.78 & 0.72 \\
\hline 70 & 0.89 & 0.86 & 0.83 & 0.78 & 0.78 & 0.72 \\
\hline 80 & 0.95 & 0.92 & 0.89 & 0.78 & 0.78 & 0.72 \\
\hline 90 & 1.03 & 0.99 & 0.96 & 0.78 & 0.78 & 0.72 \\
\hline \multicolumn{7}{|c|}{ Contribution Based } \\
\hline & \multicolumn{3}{|c|}{ Private Sector } & \multicolumn{3}{|c|}{ Public Sector } \\
\hline Percentage & HS dropouts & H.S. & College & H.S. dropouts & H.S. & College \\
\hline 10 & 0.65 & 0.54 & 0.47 & 0.66 & 0.55 & 0.48 \\
\hline 20 & 0.72 & 0.59 & 0.51 & 0.72 & 0.63 & 0.55 \\
\hline 30 & 0.77 & 0.63 & 0.54 & 0.76 & 0.71 & 0.60 \\
\hline 40 & 0.82 & 0.67 & 0.57 & 0.80 & 0.78 & 0.65 \\
\hline 50 & 0.87 & 0.71 & 0.60 & 0.85 & 0.85 & 0.73 \\
\hline 60 & 0.91 & 0.75 & 0.63 & 0.90 & 0.93 & 0.80 \\
\hline 70 & 0.97 & 0.79 & 0.67 & 0.95 & 1.02 & 0.88 \\
\hline 80 & 1.04 & 0.85 & 0.72 & 1.02 & 1.13 & 0.97 \\
\hline 90 & 1.14 & 0.93 & 0.79 & 1.13 & 1.31 & 1.13 \\
\hline
\end{tabular}


Table 7: Individual Gross Replacement Ratio: average by wage deciles

\begin{tabular}{|c|c|c|c|c|c|c|}
\hline \multicolumn{4}{|c}{ Whole Population } & \multicolumn{2}{c|}{ Private Sector } & \multicolumn{2}{c|}{ Public Sector } \\
\hline Deciles & EB & CB & EB & CB & EB & CB \\
\hline 1 & 0.922 & 1.168 & 0.968 & 1.128 & 0.774 & 1.297 \\
2 & 0.860 & 1.023 & 0.898 & 0.995 & 0.773 & 1.078 \\
3 & 0.838 & 0.947 & 0.867 & 0.930 & 0.774 & 0.982 \\
4 & 0.816 & 0.891 & 0.841 & 0.873 & 0.774 & 0.928 \\
5 & 0.801 & 0.838 & 0.815 & 0.820 & 0.773 & 0.873 \\
6 & 0.791 & 0.797 & 0.801 & 0.786 & 0.770 & 0.816 \\
7 & 0.780 & 0.748 & 0.782 & 0.740 & 0.771 & 0.769 \\
8 & 0.768 & 0.704 & 0.766 & 0.703 & 0.768 & 0.712 \\
9 & 0.753 & 0.651 & 0.748 & 0.652 & 0.762 & 0.662 \\
10 & 0.719 & 0.566 & 0.706 & 0.570 & 0.752 & 0.546 \\
\hline
\end{tabular}


Table 8: Inequality Measures

\begin{tabular}{|c|c|c|c|c|c|c|}
\hline & \multicolumn{3}{|c|}{ Earnings Based Benefit } & \multicolumn{3}{|c|}{ Contribution Based Benefit } \\
\hline & Coeff. Variation & S.D. of logs & Gini coefficient & Coeff. Variation & S.D. of logs & Gini coefficient \\
\hline Whole population & 0.37 & 0.33 & 0.19 & 0.23 & 0.22 & 0.12 \\
\hline Private & 0.36 & 0.33 & 0.19 & 0.25 & 0.24 & 0.13 \\
\hline High School Dropouts & 0.23 & 0.23 & 0.13 & 0.18 & 0.18 & 0.10 \\
\hline High School Grad. & 0.24 & 0.23 & 0.13 & 0.19 & 0.19 & 0.11 \\
\hline College Graduates & 0.22 & 0.22 & 0.12 & 0.20 & 0.19 & 0.11 \\
\hline Public & 0.34 & 0.31 & 0.18 & 0.19 & 0.19 & 0.10 \\
\hline High School Dropouts & 0.22 & 0.22 & 0.12 & 0.10 & 0.10 & 0.06 \\
\hline High School Grad. & 0.36 & 0.35 & 0.20 & 0.22 & 0.22 & 0.12 \\
\hline College Graduates & 0.38 & 0.37 & 0.21 & 0.23 & 0.22 & 0.12 \\
\hline
\end{tabular}


Figure 3: Transformed Lorenz curves, Private Sector

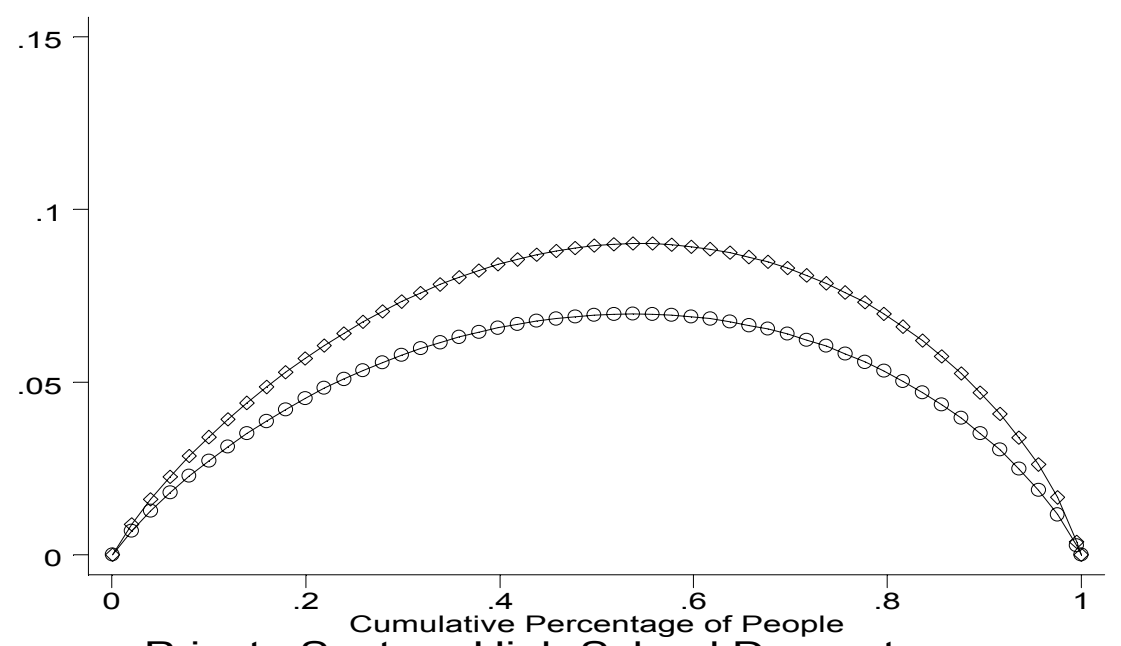

Private Sector - High School Dropouts
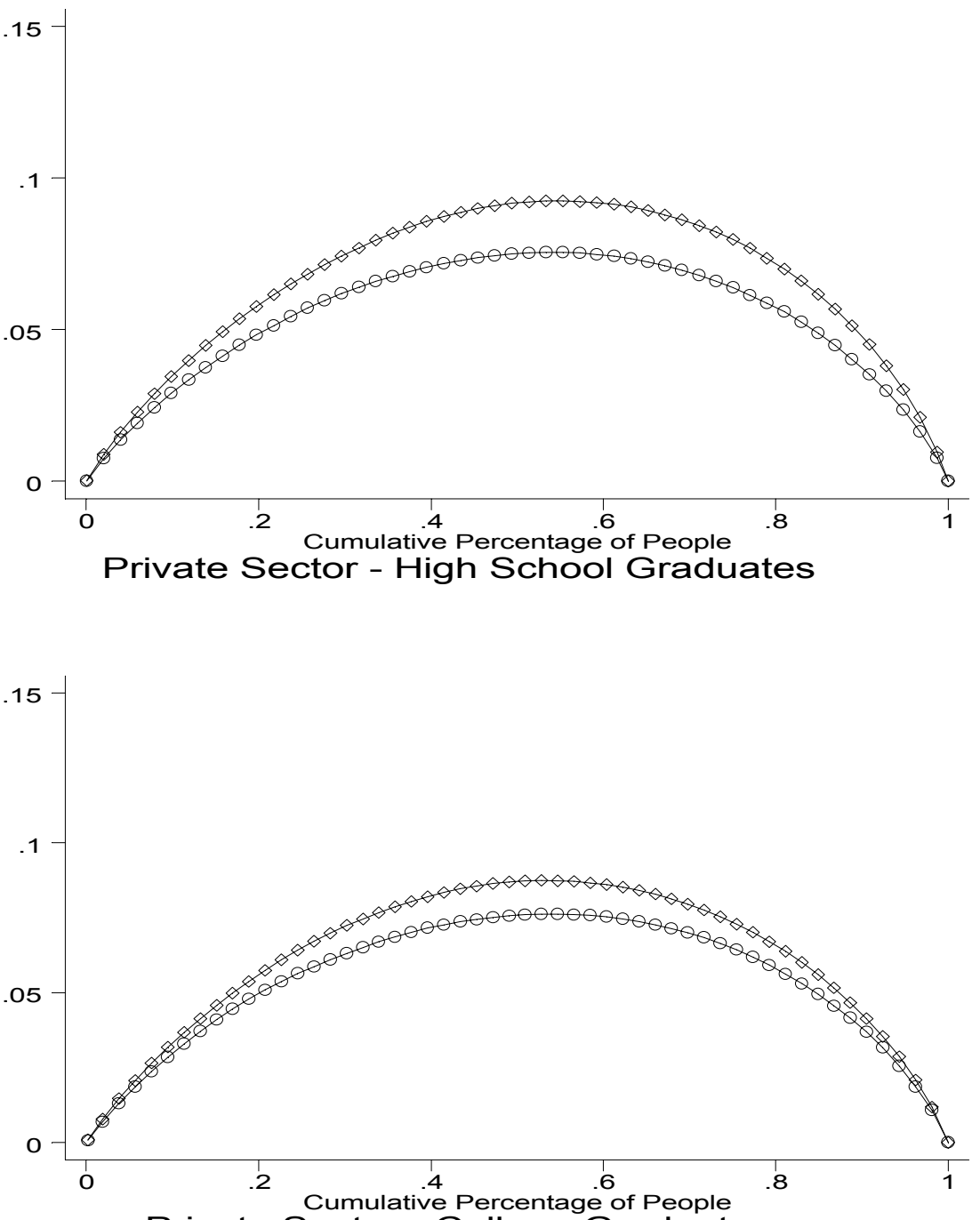

Private Sector - College Graduates

$\square$ : Earnings Based

O: Contribution Based 
Figure 4: Transformed Lorenz curves, Public Sector
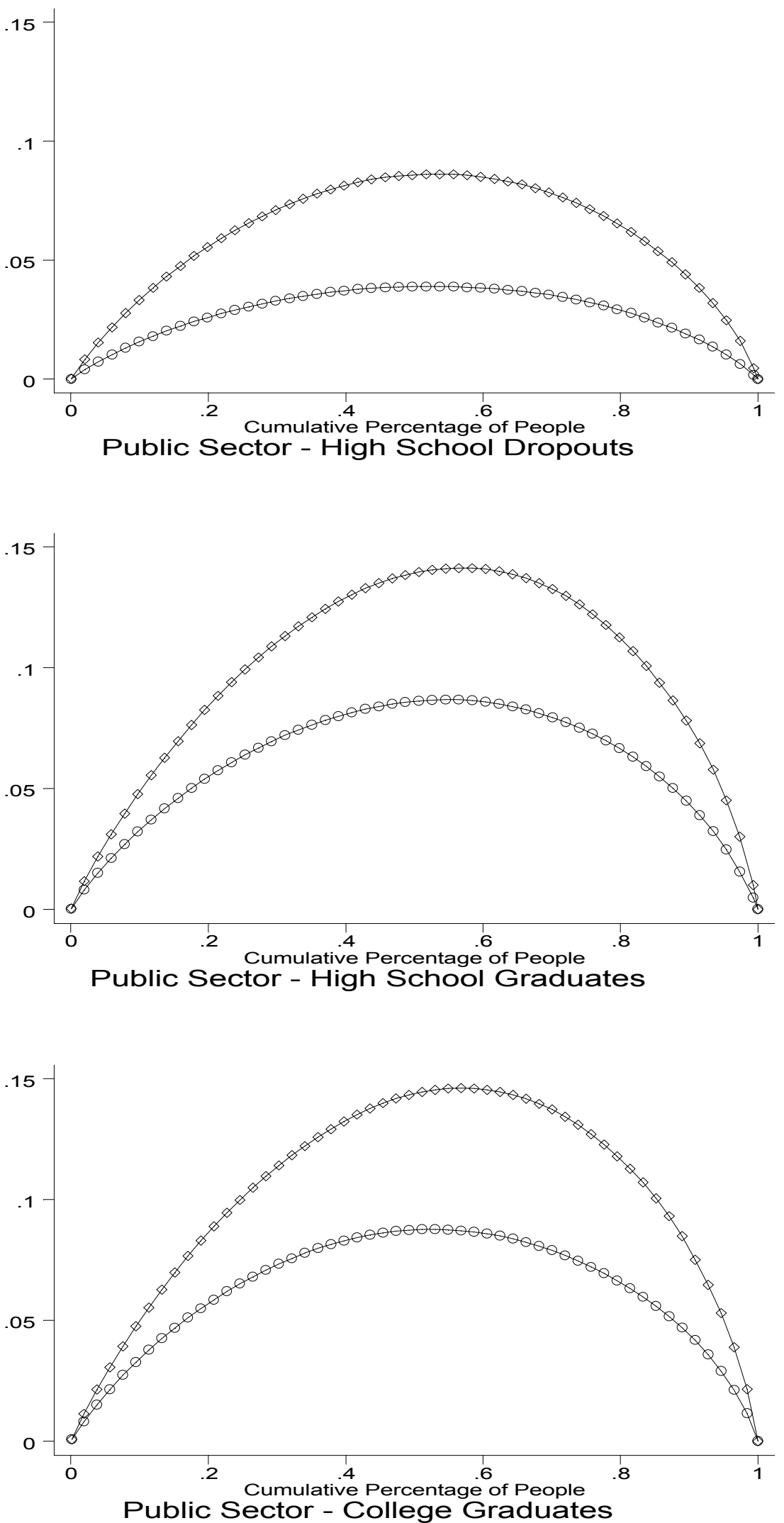

$\square$ : Earnings Based

O: Contribution Based 
Figure 5: Transformed Lorenz Curve, Private and Public Sector
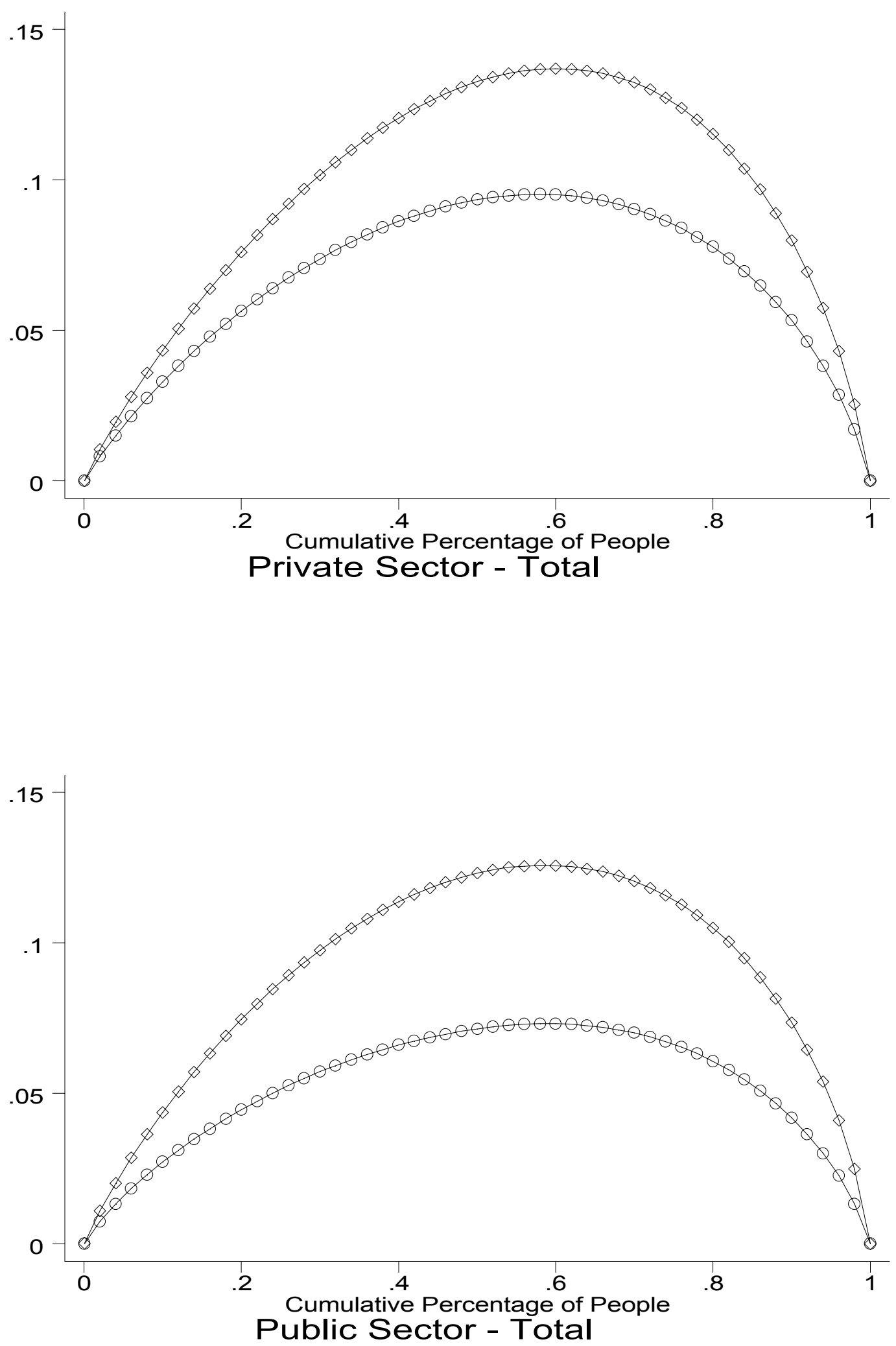

$\square$ : Earnings Based

O: Contribution Based 
Figure 6: Transformed Lorenz curve, whole population

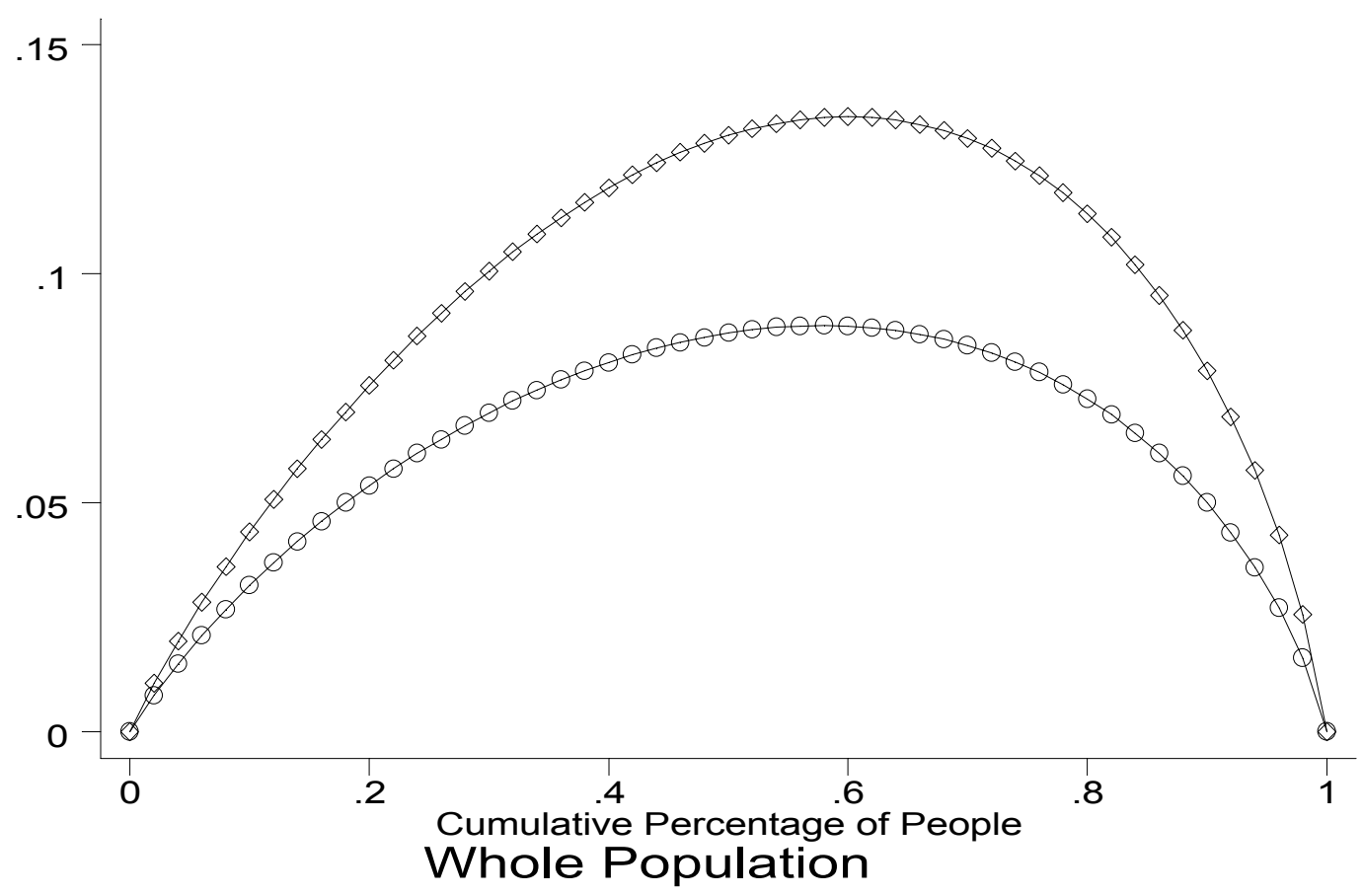

Figure 7: Generalised Lorenz curve, whole population

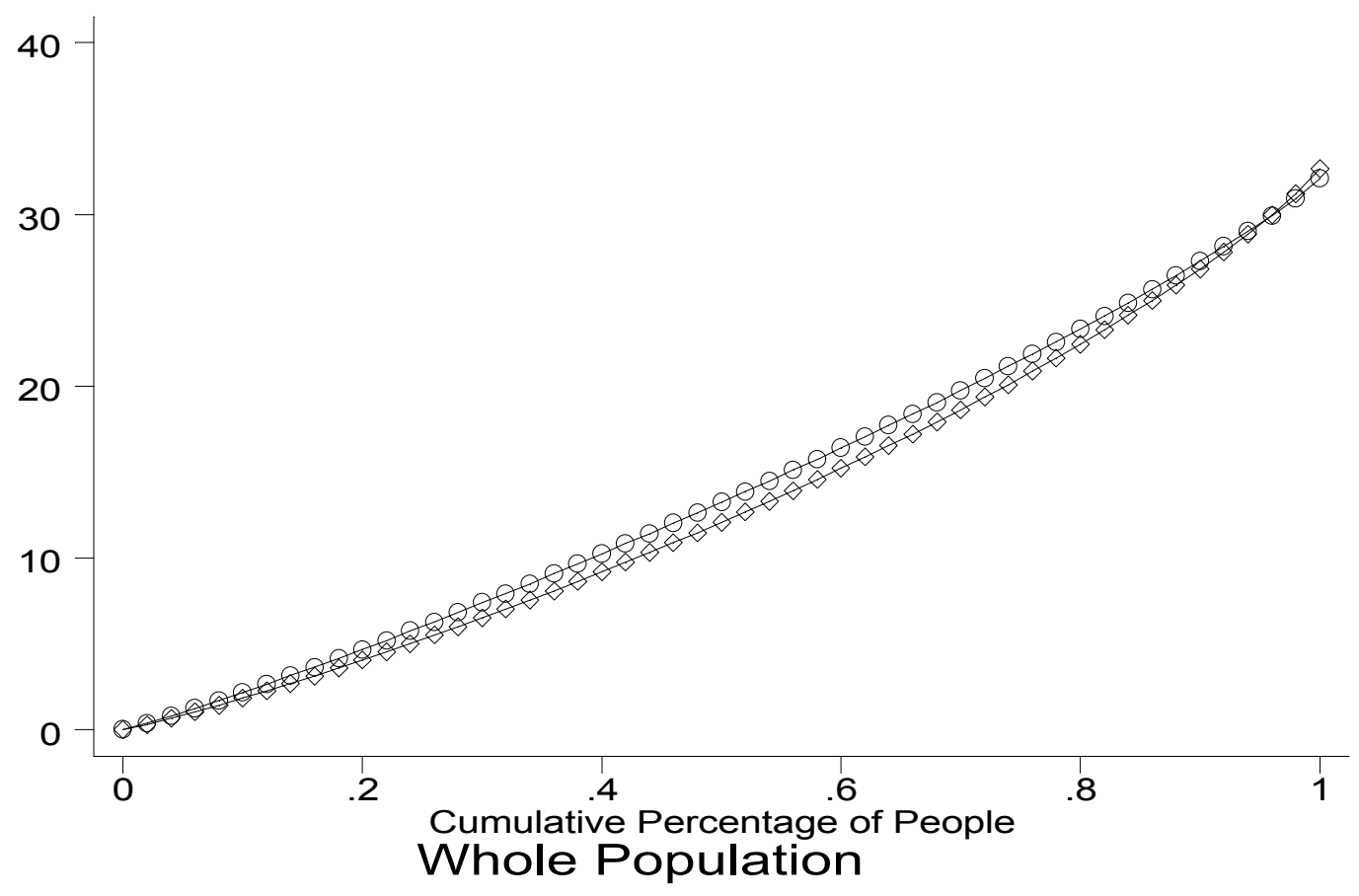

$\square$ : Earnings Based

O: Contribution Based 
Figure 8: Generalised Lorenz curve: Private Sector

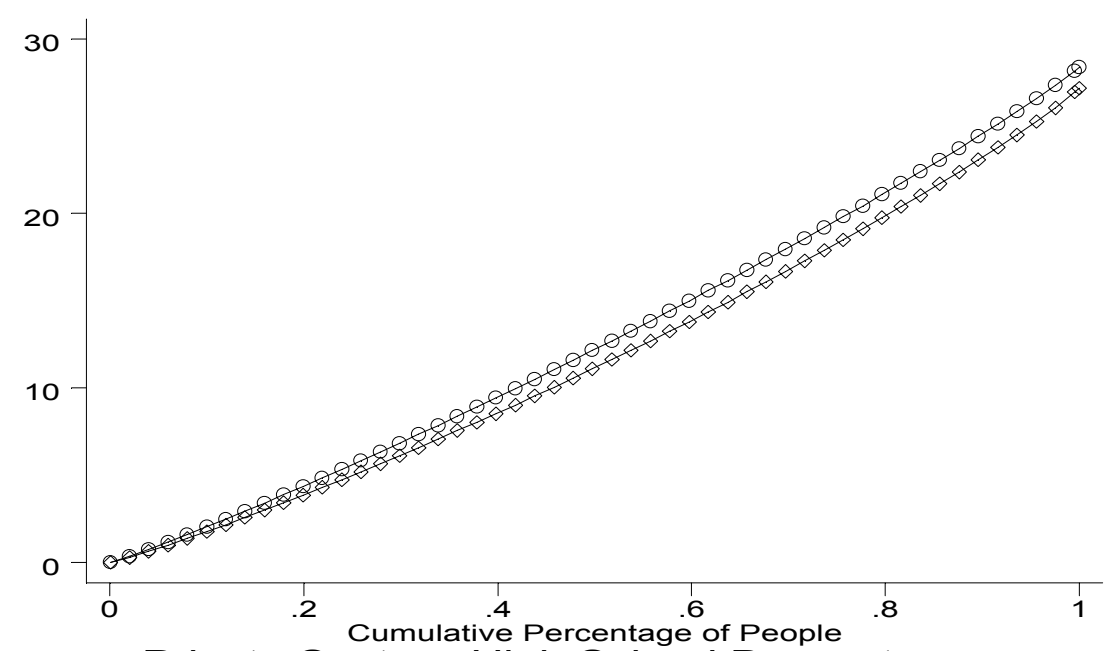

Private Sector - High School Dropouts

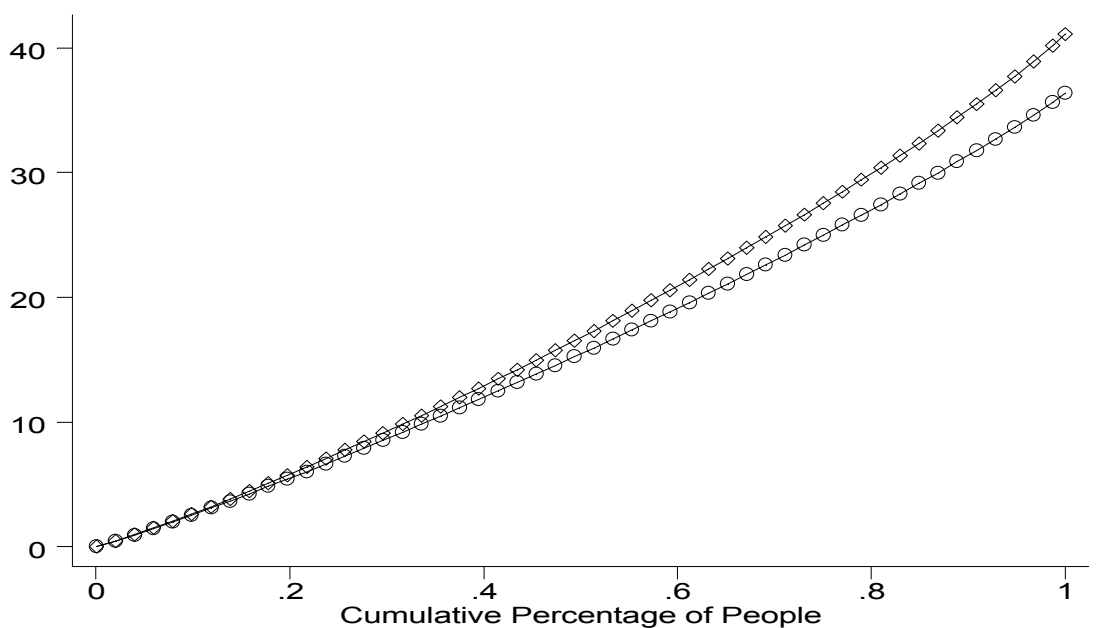

Private Sector - High School Graduates

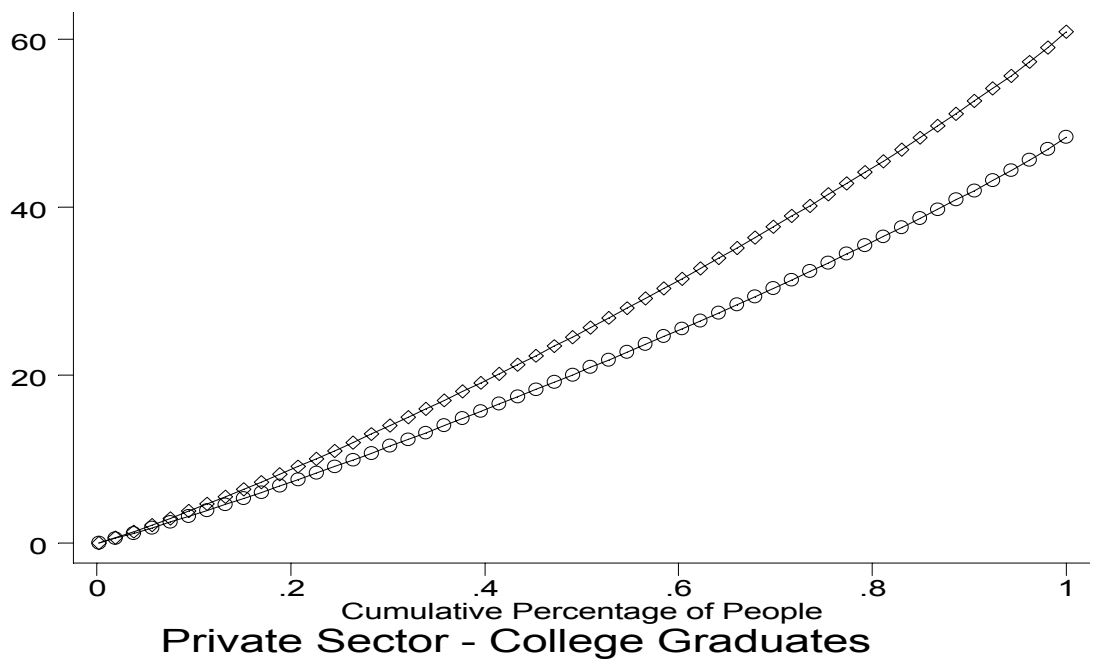

$\square$ : Earnings Based

O: Contribution Based 
Figure 9: Generalised Lorenz curve: Public Sector

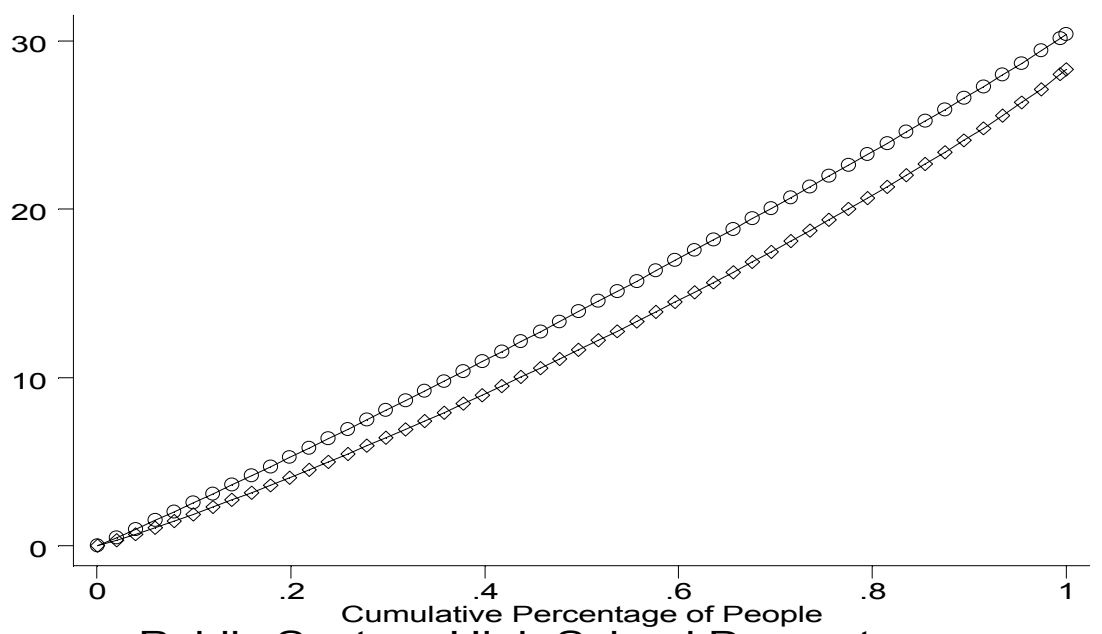

Public Sector - High School Dropouts
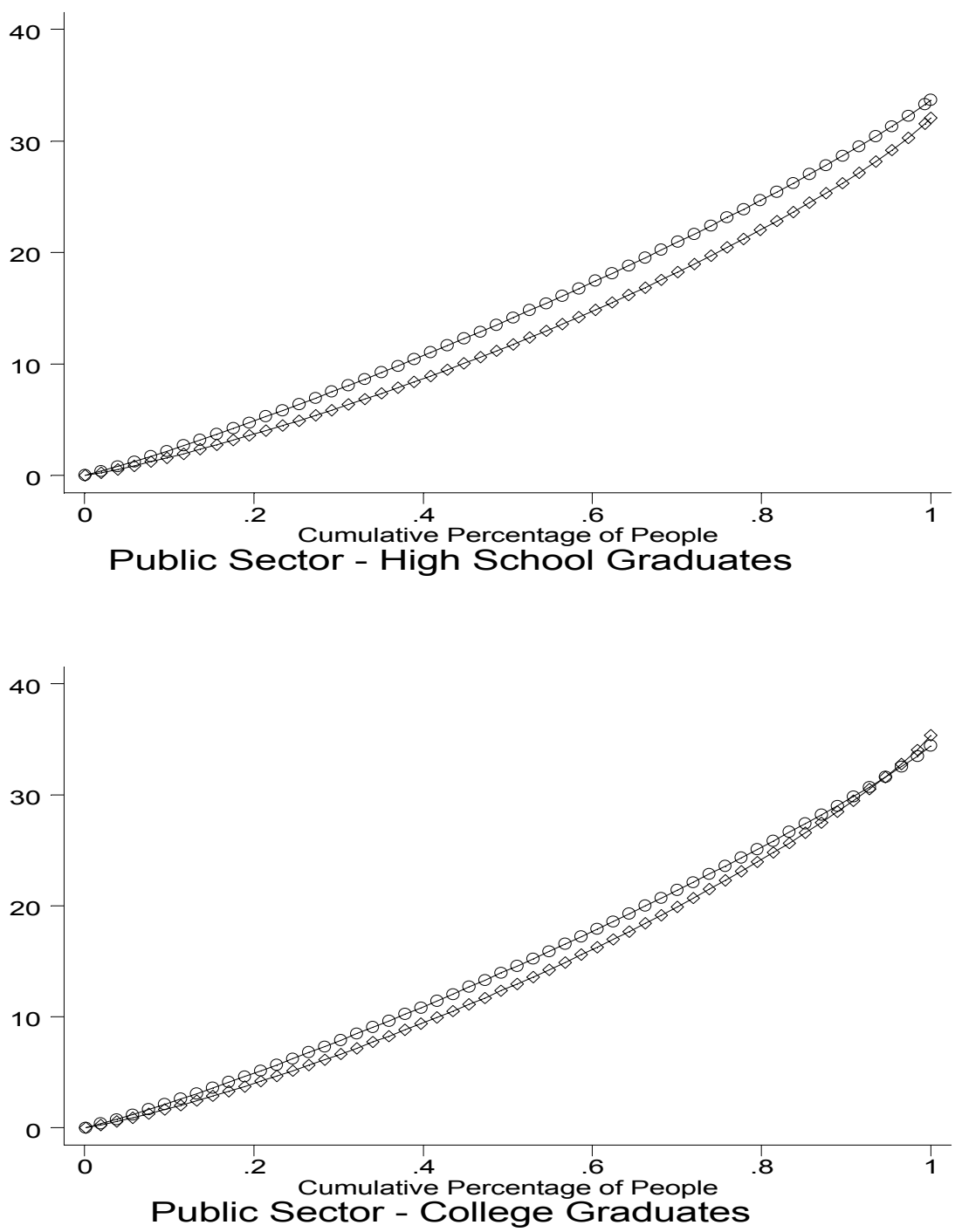

$\square$ : Earnings Based

O: Contribution Based 
Figure 10: Generalised Lorenz Curve, Private and Public Sector
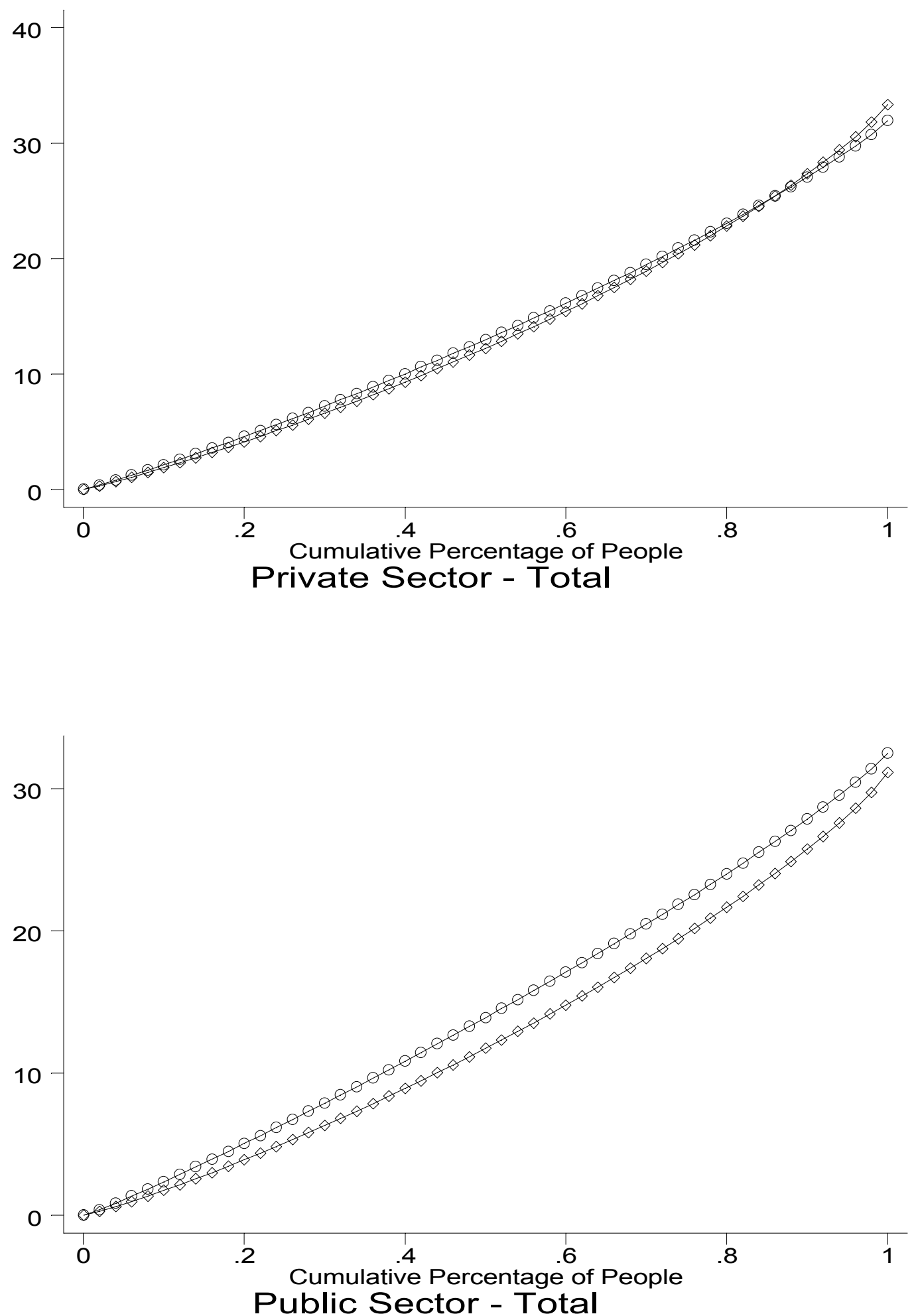

$\square$ : Earnings Based

O: Contribution Based 
Our papers can be downloaded at:

$$
\text { http://cerp.unito.it }
$$

CeRP Working Paper Series:

$\mathrm{N}^{\circ} 1 / 00 \quad$ Guido Menzio

$N^{\circ} 2 / 00 \quad$ Pier Marco Ferraresi Elsa Fornero

$\mathrm{N}^{\circ} 3 / 00 \quad$ Emanuele Baldacci Luca Inglese

$\mathrm{N}^{\circ} 4 / 01 \quad$ Peter Diamond

$\mathrm{N}^{\circ}$ 5/01 Vincenzo Andrietti
Opting Out of Social Security over the Life Cycle

Social Security Transition in Italy: Costs, Distorsions and (some) Possible Correction

Le caratteristiche socio economiche dei pensionati in Italia. Analisi della distribuzione dei redditi da pensione (only available in the Italian version)

Towards an Optimal Social Security Design

Occupational Pensions and Interfirm Job Mobility in the European Union. Evidence from the ECHP Survey

$N^{\circ}$ 6/01 Flavia Coda Moscarola The Effects of Immigration Inflows on the Sustainability of the Italian Welfare State

$\mathrm{N}^{\circ} 7 / 01 \quad$ Margherita Borella

The Error Structure of Earnings: an Analysis on Italian Longitudinal Data

$N^{\circ} 8 / 01$ Margherita Borella Social Security Systems and the Distribution of Income: an Application to the Italian Case 